\title{
GIS ANALYSIS OF THE SEISMIC DAMAGE ON HISTORICAL MASONRY SPIRES
}

\author{
E. Zanazzi ${ }^{1 *}$, E. Coïsson ${ }^{1}$, D. Ferretti ${ }^{1}$ \\ ${ }^{1}$ DIA, University of Parma, Parco Area delle Scienze 181/A, 43124 Parma, Italy - (elena.zanazzi, eva.coisson, \\ daniele.ferretti)@unipr.it
}

Commission VI, WG VI/4

KEY WORDS: spire, seismic damage, proactive geodatabase, architectural heritage

\begin{abstract}
:
The Emilia 2012 earthquake highlighted the high vulnerability of historical masonry spires, at the top of bell towers. Indeed almost half of the spires, in the area hit by the seismic event, show the loss of the top. The observed collapse mechanism consists in sliding of the spire top and in the resulting overturning. Once the emergency phase has passed, it is now a duty to learn from this traumatic experience and to provide new tools for the prevention of the destructive effects of future earthquakes. In this perspective, a geodatabase was designed, using the ArcGIS Pro software, for monitoring the vulnerabilities of the surveyed spires. Indeed, as we learn from the study of the effects of past earthquakes, seismic damages are recurrent for each building typology and therefore they can be predictable and avoidable. For example, by statistically elaborating the data of the designed database, a correlation arose between the levels of damage of the spires and their type of masonry arrangement. Indeed four different masonry typologies have been distinguished. The work then focuses on three damaged spires of churches belfries, proposing three consolidation hypotheses to prevent the future loss of the rebuilt top part of the spire. The structural analyses, performed with Abaqus CAE and detailed in a different work, showed that the same intervention produces different results on the different case studies: a demonstration that there is not an "absolute" best solution, but an intervention suitable for each case.
\end{abstract}

\section{INTRODUCTION}

Italy has a long experience on the effects of earthquakes on its vast cultural heritage: the observation of centuries of damages highlighted not only the vulnerability of the historical architectural heritage, but also the inadequacy of the tools usually adopted for the prevision of their seismic behaviour. To foresee the vulnerabilities of historical masonry buildings it is instead necessary to take a step backwards and adopt an empirical approach, i.e. to start from the observation and analysis of past damages (Lenticchia and Coïsson 2017a), as our ancestors did before the introduction of calculation methods in engineering. In the last century, the empirical approach was progressively forgotten although it has been widely recognized that specific recurring damages correspond to specific macro-elements of buildings, depending on their constructive typologies.

In this regard, the earthquake of Friuli in 1976 was probably the first occasion in which a detailed study was carried out with this approach in modern times, studying the real earthquake effects on specific masonry structures, such as churches (Doglioni et al., 1994). These studies were at the base in 2008 of the first Italian Guidelines for the assessment and the reduction of the seismic risk on cultural heritage (later updated in D.P.C.M 09 February 2011), which report the table of the damage mechanisms for churches, identifying the macro-elements and associating one or more recurring mechanisms to each of them. Among the macroelements, indicated in the table of the collapse mechanisms for churches, there is also the spire architectural element (Nr. 26), with its own collapse mechanism (Figure 1, left). The 2012 Emilia earthquake has demonstrated the frequency of onset of this damage mechanism: nearly half of the brick masonry spires present in the hit area were damaged and most of them suffered the complete collapse of the top part (Fig. 2, left). Also in the most recent destructive event in central Italy, several spires were similarly affected (Fig. 2, right).

Despite the clear importance of this phenomenon for the conservation of historical belfries, which represent a distinctive element of the landscape in Italian and European towns (Causevic 2019), there is a very limited number of researches dedicated to spires and their damage (Ferretti and Coïsson 2014, Dizhur 2010, Mehrotra 2017). Often they are related to similar topics, but they are not specific to the type of conical brick masonry spires here analysed, whose shape dates back to the Romanesque period, but rather to more slender stone masonry spires typical of gothic architecture (De Jong, 2012a, Cigada et al 2016, Elyamani 2016, ) or to building techniques and shapes typical of other countries' cultural tradition (Dogangun 2007). Moreover, the specific damage analysed in the present work, i.e. the loss of the top part of the spire, was neglected in nearly all the published works on the seismic behaviour of historical masonry belfries, towers or minarets topped by spires (Bayraktar 2011). When numerical analyses are carried out, they usually do not highlight this type of possible damage (Nohutcu 2019), demonstrating the inadequacy of these tools if applied disregarding a strict contact with the observation of the real building and of experience.

In the Italian technical code for the prevention of seismic risk (D.P.C.M 09 February 2011), as aforesaid, among the kinematic mechanisms for churches, mechanism n.26 indicates an inclined fracture plane as the most probable expected damage in spires (Figure 1). However, more frequently, the shocks of May 2012 produced horizontal cracks, originating from the shear in the mortar joints, which led to the separation and slip of the top of the spire, and possibly to the bending moment that could induce overturning (Ferretti and Coïsson, 2014a). This mechanism occurred very often in earthquake struck areas, even in the absence of other cracks in the stem of the bell tower (Blasi, 2013).

\footnotetext{
* Corresponding author
} 
In many cases, only the top stone element fell down. In other cases, the sliding mechanism also affected a part of the underlying masonry.

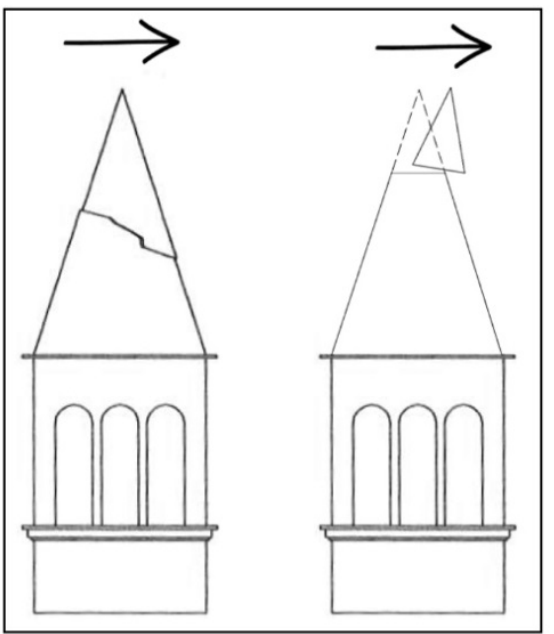

Figure 1. The damage mechanism of Italian Guidelines (left) and the most commonly observed mechanism (right).
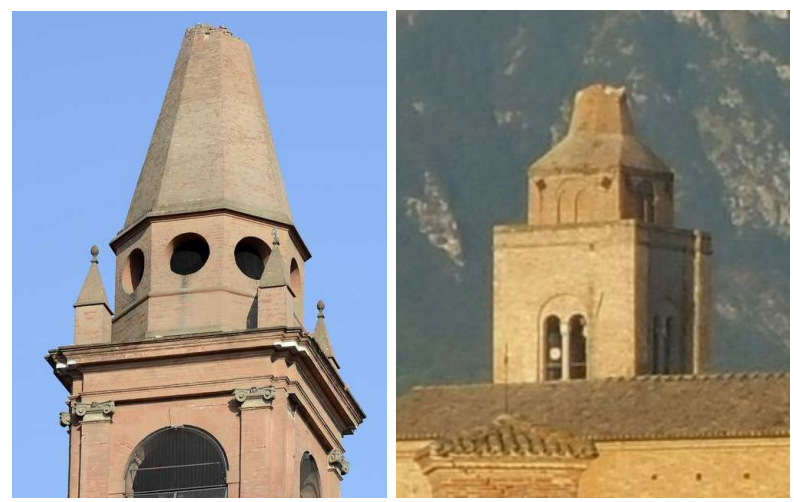

Figure 2. Damages to belfries spires in the 2012 Emilia earthquake (left) and in the 2016 Central Italy earthquake (right).

\section{BRICK MASONRY ARRANGEMENTS IN SPIRES}

The first observations on the damaged spires after the Emilia 2012 earthquake suggested that their construction technology could have an effect on their behaviour: indeed, the presence of iron ties, inside the masonry, and geometric or material discontinuities can influence the point of the crack onset. It seemed therefore necessary to focus on the technological features of the masonry spires in this area, which are usually built with ad hoc bricks. The spires are often topped by a stone tip, linked to the underlying masonry whit iron ties. Therefore the masonry of spires is often characterized by geometric and material discontinuities. These particular constructive features can influence their seismic behaviour. It was possible to distinguish at least four typologies of masonry arrangements, represented in Figure 3.

Type 1: Rounded wedge-shaped bricks arranged radially and with alternating courses. The spires with this arrangement have predominantly a conical shape. This particular type characterizes several spires located in the southern area of Mantua, for example the spires for church Sant'Erasmo of Governolo, in Roncoferraro.
Type 2: Wedge-shaped bricks similar to the above-mentioned ones, but with a flat outer side, thus the external surface of the spire is smooth, creating flat sides of usually pyramidal spires. Moreover, some spires have couples of larger bricks placed along four perpendicular axes, shaping four vertical ribs. For instance, this solution is present in spires of the Collegiate Church of San Biagio di Cento, Ferrara.

Type 3: Square bricks distributed at alternating courses, arranged at $45^{\circ}$ radially. This arrangement might be the reason of serious erosion and other decay phenomena, which characterize the external side of these bricks, thus the extrados of the spire is a very complex surface, while the intrados of the cone is smooth, because bricks were arranged radially in rowlock courses. An example of such a solution is the spire of S. Andrea di Ghisione in Villa Poma, Mantua.

Type 4: Stretcher bricks: one or two masonry leaves, with bricks arranged in alternating stretcher courses. There is a better connection at the corners, compared to other masonry arrangements. This typology is often used in the more recent spires.

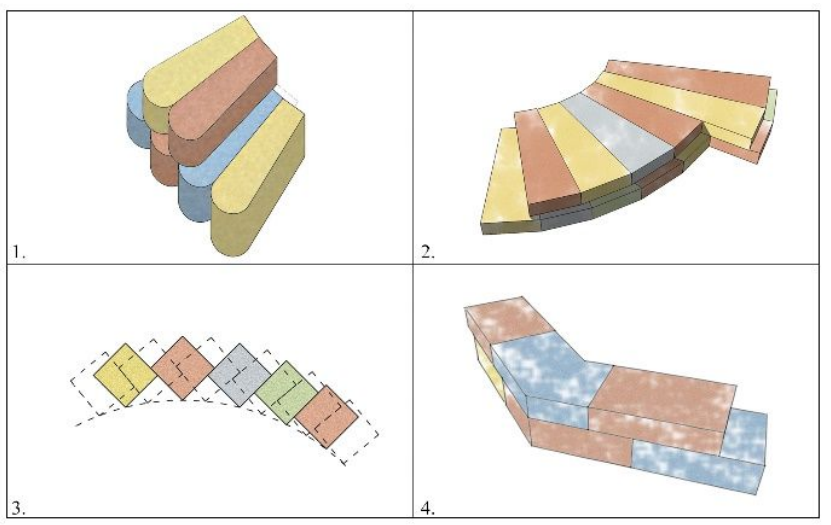

Figure 3. The four typologies of masonry assessment used to build the spires.

\section{A GEODATABASE FOR THE SPIRES}

\subsection{GIS as a proactive tool}

Nowadays, new tools can be applied to analyze big data about the past seismic damages in order to make statistical assessments on the relation between building features and type of damage, thus inferring useful indications for future preventive interventions. The large number of spires in the seismic area, nearly one hundred, made indeed necessary the use of a systematic and organized cataloguing through a Geographic Information Systems (GIS). In particular, ArcGIS Pro software (ESRI, 2019) was used to collect the data of 77 belfries with spires, whose main features are reported in Table 1 . The credit of this system consists in the possibility of connecting information of any kind, whether numerical or textual, to spatial coordinates in a geographical reference system, i.e. to locate the objects surveyed in the territory, with a few meter error margin.

While, on one hand, these advantages of GIS are widely known and often used for cataloguing cultural heritage assets (Di Cocco, 2014), on the other hand, this tool is not always exploited in all its potential. Some cases exist of similar applications to different building typologies, like fortified architecture (Coïsson et al 2017). 


\begin{tabular}{|c|c|c|c|c|}
\hline \multirow{2}{*}{ CATALOGUED SPIRES } & \multicolumn{2}{|c|}{ DAMAGED SPIRES } & \multicolumn{2}{c|}{ DAMAGED BEFORE 2012 } \\
\cline { 2 - 5 } & Yes & No & Yes & No \\
\hline 77 & 39 & 38 & 9 & 68 \\
\hline
\end{tabular}

\begin{tabular}{|c|c|c|c|r|r|}
\hline \multicolumn{3}{|c|}{ MATERIAL OF TIP } & \multicolumn{2}{c|}{ GEOMETRY } \\
\hline Stone & Concrete & Metal & Not available & Cone & Pyramid \\
\hline 30 & 14 & 26 & 7 & 34 & 43 \\
\hline
\end{tabular}

\begin{tabular}{|l|c|c|c|}
\hline SEISMIC ZONE & 2 & 3 & 4 \\
\hline Total spires & 4 & 71 & 2 \\
\hline Damaged spires & 0 & 39 & 0 \\
\hline
\end{tabular}

\begin{tabular}{|c|c|c|}
\hline \multicolumn{3}{|c|}{ CONSTRUCTION CENTURY } \\
\hline Before 16th & From 16th to 18th & After 18th \\
\hline 11 & 39 & 27 \\
\hline
\end{tabular}

Table 1. Main data about the spires included in the proposed GIS to catalogue the damage in the 2012 Emilia earthquake.

In the present work the designed geodatabase (initially proposed in Zanazzi, 2017) does not want to be just a "passive" storage system, but also a proactive tool for forecasting and preventing seismic risk. The system indeed can be queried to understand the real vulnerabilities of the studied assets. This tool could allow their immediate and correct identification on the territory; not only in the emergency phase, in order to ensure a faster first intervention; but also in current management. For these reasons, the use of the GIS system is not only useful, but is indispensable today, and was adopted for the management of the cultural heritage also in the area hit by the 2012 earthquake (Di Cocco, 2014).

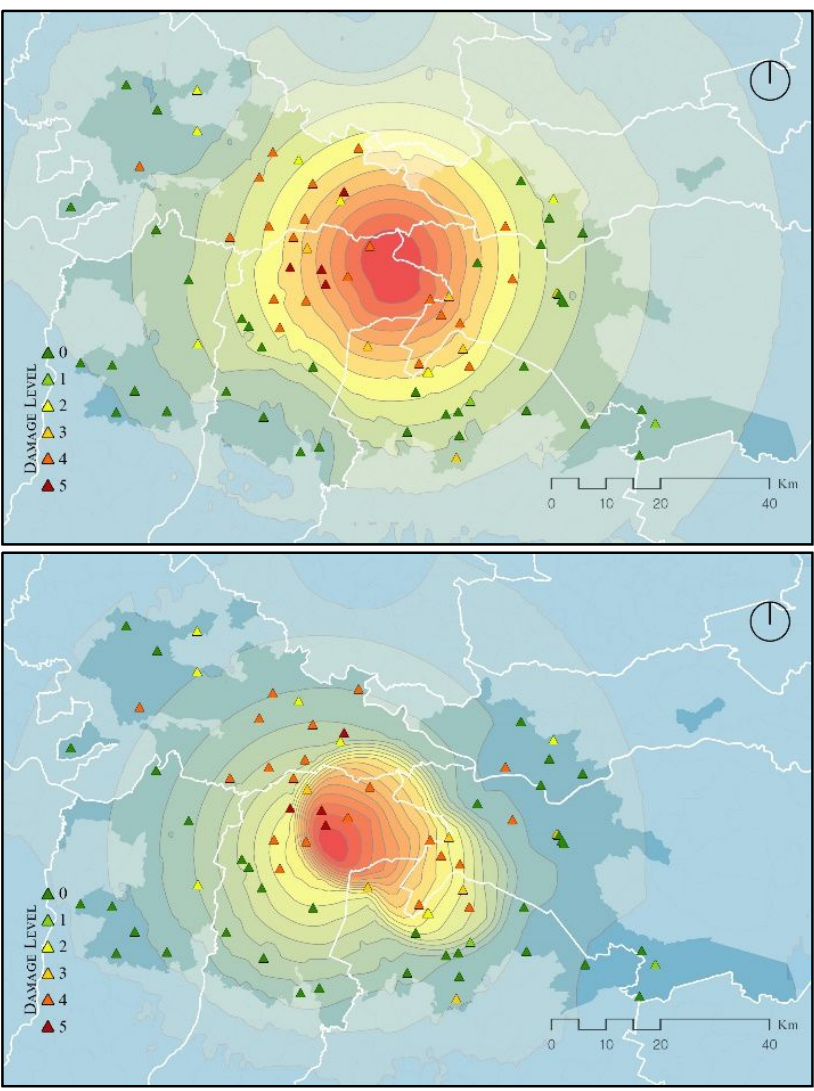

Figure 4. The shakemaps of the main 20 May shock (top) and of the main 29 May shock (bottom).

In this perspective, the proposed geodatabase was implemented with the shakemaps (Figure 4) of the two main shocks of 2012 May earthquake: 20 May at 02:03:52 UTC and 29 May at 07:00:03 UTC (Arcoraci et al., 2012). Shakemaps are a graphic representation of the soil motion (in terms of acceleration, velocity, or displacement), recorded by seismometers and properly interpolated in the map. In particular the employed shakemaps had as unit of measurement PSA (Spectral Response), recorded with a period $T$ of $0.3 \mathrm{~s}$. This small value of the period was chosen because almost all spires belong to bell towers adherent to other structures, which reduce their height. Shakemaps are produced in real time by INGV, downloadable as shapefile (INGV 2019; USGS 2019) and therefore easily uploaded in the GIS. These maps are functional to a rapid assessment of the seismic event and its diffusion. Including these maps in the geodatabase allowed to define the seismic action to which each geo-referenced asset was subjected, in order to have a more precise correlation between action and damage.

\subsection{Geodatabase design}

Before proceeding with data entry on ArcGIS Pro, it was necessary to define the logical and physical models at the base of the geodatabase (ESRI, 2019). These models are schemes that translate the real world entities and phenomena into organized data, readable by the GIS (Goodchild. et al., 1991; Steinitz, 2012). The logical model describes the types of relationships between the various entities of the geodatabase. The feature class "spires" is the main subject, to which all the others have been connected. These links were made through common fields, in the attribute tables of each features class. For example, the "spires" and "municipality" feature classes have been connected to each other through the field about ISTAT code of the municipalities, functional to the connection, because it was composed of numbers, thus it was easily readable by the software. In this way, the single feature classes in the database do not remain simply overlapped, but they are linked to each other through cardinality relationships. These links defined a logical model, delineated by the operator in a subjective way, which depended on the purpose with which the geodatabase was designed.

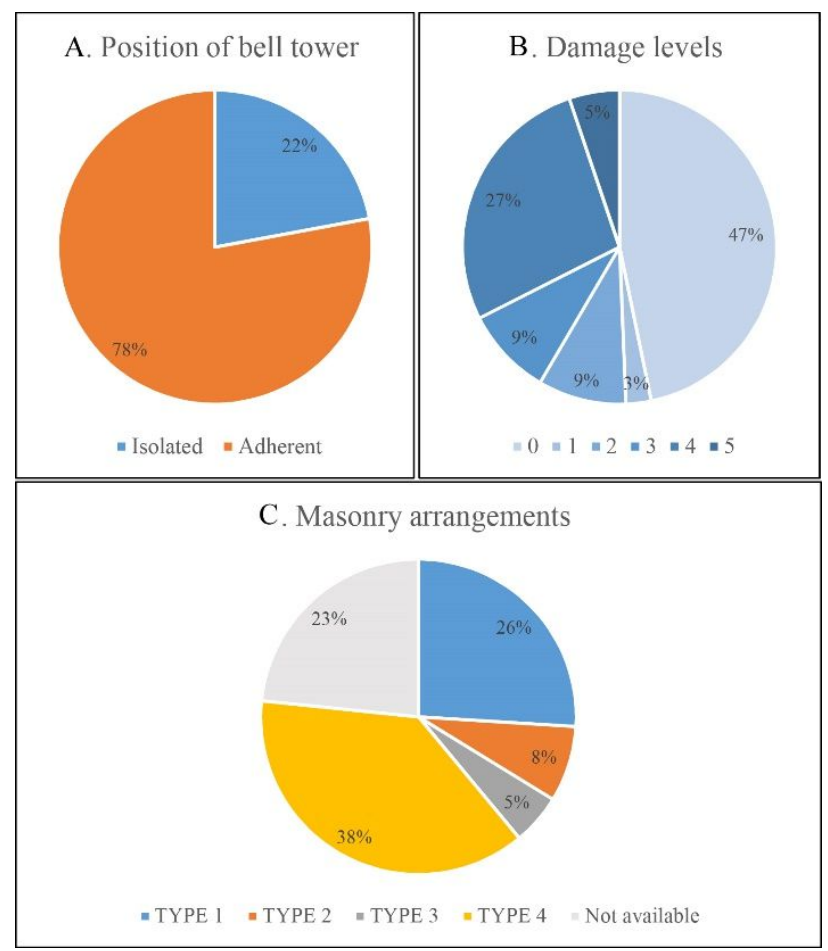

Figure 5. Charts showing the distribution of the features characterizing the spires in the analysed area and their level of seismic damage. 
The physical model defines, for each feature class, the geometry and the geographic reference system. In the database the spires are points, defined on a coordinate system (latitude and longitude) of the WGS84 UTM 32 reference system. Furthermore, the physical model identified as many features of the spire as possible. Each point has been associated with more than thirty fields, defining a large archive of information, organized in tabular files. These fields not only described the surveyed assets, but also made the second phase of querying more effective.

The fields which were more significant in the query phase (reported graphically in Figure 5), are: the maximum acceleration suffered; the belfry position (isolated or adherent to other structures, Fig. 5A); the masonry technology (Fig. 5C); and finally the level of damage suffered (Fig. 5.B), which is defined based on the photographic material available. The levels were organized on a scale from zero to five; in which zero represents the absence of damage and five the collapse of the spire's top. Level one corresponds to slight cracks, which did not interest the structural part, for example metallic coating or weathervane. Level two regards not serious crack of the structural part. Level three means serious crack and the loss of coherence of the spire top with the underling masonry cone, but without collapse. Level four corresponds to an evident sliding of the top of the spire, but without the loss of the upper part of the spire. Level five indicates the overturning of the top and so its collapse.

\section{GIS QUERY AND RESULTS}

Through the ArcGIS Pro software it was possible to compare the damage levels, assigned to each spire, with the accelerations suffered during the seismic shock of May 2012. However, it was not possible to establish, in most cases, whether the level of damage assigned was the consequence of the first or of the second shock. For this reason, it was decided to create a new field that was filled in with only the maximum acceleration between the two main shocks. Of course, this does not take into account the cumulative damage that could be induced by the second shock on already hit structures, but it seems reasonable to quantify the larger action that hit the asset. The PSA values were then divided into appropriate ranges to allow a more comprehensible and easy reading. Indeed, overlapping the shakemaps of the two shocks, made it possible to show that the most damaged spires were located in the area between the two epicentres (Figure 6). This relation did not emerge by comparing the distribution of damage levels with only one of the two shakemaps (Figure 4).

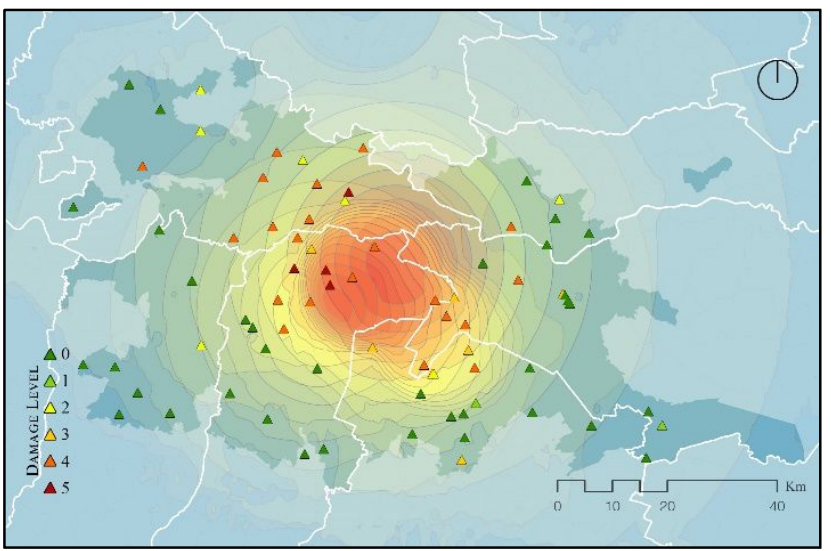

Figure 6. The superimposed shakemaps of the two main shocks of 20 and 29 May 2012, and the damage levels of the spires.
After this territorial study, a statistical analysis on the collected data was performed. In particular, Figure 7 shows the distribution of relative frequencies of damaged spires (damage level 4) for different PSA. Data have been divided considering the type of spire and the connection of the belfry. Figure 7 show how some spires are more, or less, resistant than others to the earthquake. Indeed, with the same acceleration, the spires made with the square brick technique (type 3 in Figure 7) are more seriously damaged. On the contrary, the spires made with stretcher bricks (type 4, in Figure 7) are less vulnerable.

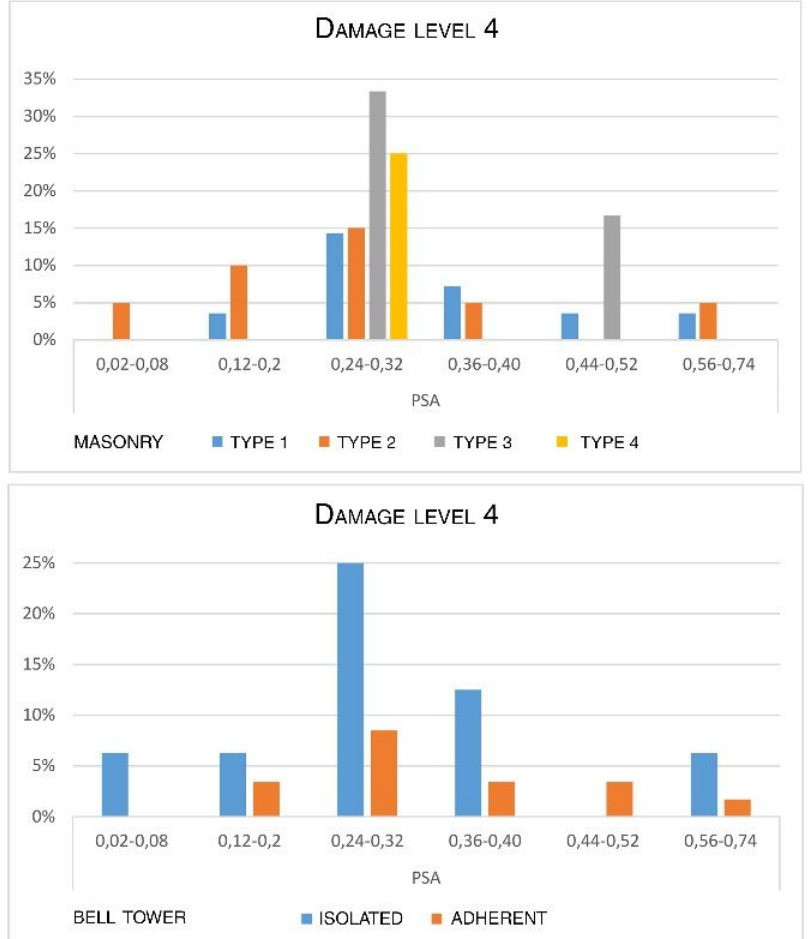

Figure 7. Frequency distribution of damaged spires as a function of PSA. The relationship between PGA and the masonry arrangement typologies (top) and with the bell tower position (bottom).

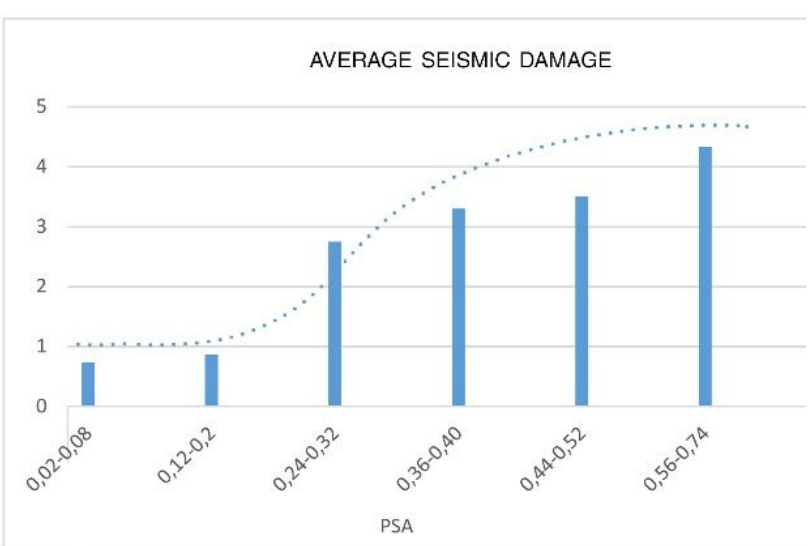

Figure 8. Curve relating the damage levels and the PSA value.

Of course, subdividing the data in different typologies and different levels of damage can result in a limited number of cases for each slot, limiting the significance of the statistical analyses. Widening the research, e.g. also including the data from the recent Central Italy earthquake, possibly also with different constructive techniques, will allow increasing the impact of the results in terms of relevance and representativeness. 
Considering the geolocation of the spires and their construction period evidences that the spires in the Ferrara area were generally built after the 16th century earthquakes (Guidoboni and Boschi, 1991). The oldest spires are located in the low Mantua or North of Modena, which was not historically subject to serious seismic stresses (USGS, 2018; Baratta et al. 1901). Furthermore, the most modern spires (built in the 20th century) are in area of Reggio Emilia, which was affected by seismic event in XVII century, of which however we do not have certain information (INGV, 2018).

The statistical analysis also pointed out that, with the same acceleration, the spires belonging to the bell towers adherent to other structure are less damaged than the ones on free standing belfries (Figure 7). This is probably due to the fact that they are subjected to smaller displacements. Isolated belfries, instead, are subjected to larger displacements and consequently the whip effect of the trunk movement induce more damages on the top element. On the contrary, a greater vulnerability of the trunk in the case of adherent or incorporated bell towers was observed, compared to the isolated ones. Indeed, the latter could oscillate and, unless particular constructive incongruities, they were not seriously damaged: Isolated belfries could be considered as onedimensional cantilevers fixed at the ground, which might in turn reduce the frequencies. On the other hand the bell towers adherent to other building, such as churches, have usually shown more serious damages to their trunks, because of hammering effects, which caused sub-horizontal fractures on the stem of belfries (Blasi, 2014).

In Figure 8 the level of damage is related to the PSA; it is possible to identify a threshold at about $0.2 \mathrm{~g}$ under which the expected damage is limited or absent. Above that value, the damage was always at least at level 3, corresponding to serious structural damage, but without collapse. These data help to understand which are the main vulnerabilities of the architectural heritage, widespread in the territory, and this is of vital importance in order to establish a list of intervention priorities, to act now and prevent the future damages.

\section{THREE CASE STUDIES AND STRENGTHENING PROPOSALS}

With the aim of adopting the indications that arose from the GIS as a tool for the identification of the most urgent interventions, the work then focuses on three spires of churches belfries, characterized by different features:

- San Nicola di Bari in Cortile (Carpi, Modena);

- Sant'Egidio in Cavezzo (Modena);

- Sant'Agostino in Sant'Agostino (Ferrara).

All three bell towers have shown the damage mechanism of loss of the top part of the spire, but they had three different masonry arrangements: the spire of San Nicola in Cortile presents square bricks, arranged at $45^{\circ}$ (type 3 ); the spire of Cavezzo is composed by wedge-shaped bricks with a flat outer side (type 2) and the spire of Sant'Agostino is made of stretcher bricks (type 4). Moreover, all these bell towers were built isolated, however the belfry of Sant'Egidio in Cavezzo was built too close to another structure and, during the shock of May 20 (with a PSA of $0.28 \mathrm{~g}$ ), a hammering effect arose, which caused a severe crack pattern to the stem of the bell tower. Instead, the other two bell towers were seriously damaged by the main shock of May 29, with a PSA of $0.36 \mathrm{~g}$.
After the examination of the intervention proposed in the restoration projects for other damaged spires, three consolidation hypotheses (Figure 9) were studied to assess their effectiveness in preventing the loss of the top part of the spire after its reconstruction:

- a single connection spring between the tip and the bells structure;

multiple springs of connection between the tip and the bells structure;

- a mass hung to the tip of the spire.

The three bell towers were modelled with Finite Elements (Abaqus) and both static and dynamic analyses were performed in order to test the behaviour of the spires with and without strengthening. The details of the analyses are reported in (Zanazzi, 2017).

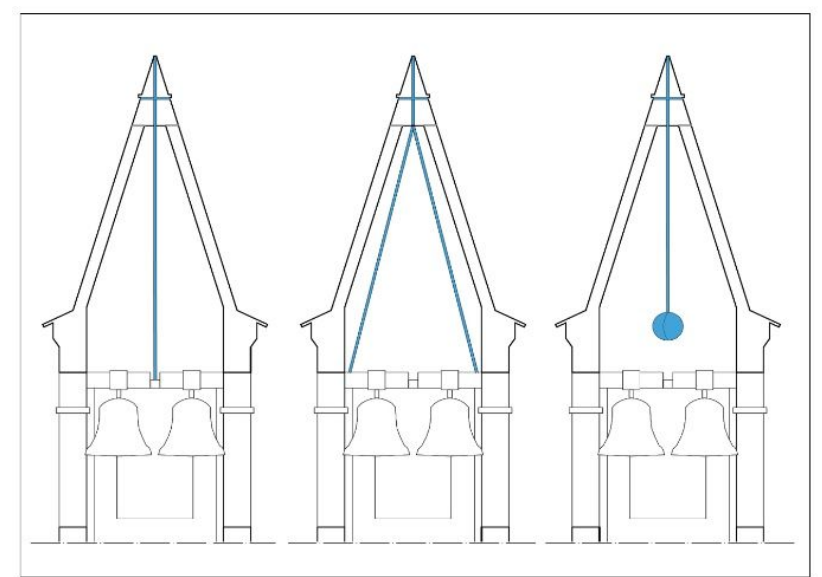

Figure 9. The three strengthening proposals, applied to the spire of S. Nicola di Bari in Cortile. From left: single spring, multiple springs, hanging mass.

The numerical results showed that the same type of intervention has a different effectiveness on the different structures and the best solution among the proposed ones changes in the different cases. This is another confirmation that when dealing with existing historical structures, the intervention proposals, in compliance with the principles of restoration (reversibility, compatibility, minimum intervention, recognisability), need to be declined and adapted to the different characteristics of the single cases. For example in the second solution, the springs were distributed differently for the spire of Cortile di Carpi (three springs at $120^{\circ}$ ) and in the other two octagonal spires (four springs at $90^{\circ}$ ), following their geometrical characteristics. Moreover, the results showed that the hanging mass could have a positive effect in the spires of Cavezzo and Cortile di Carpi, reducing the shift of the top, but negative in Sant'Agostino, where the non-linear dynamic analysis demonstrated the increase of the shift of the spire's top in case of earthquake after this intervention.

\section{CONCLUSIONS}

The analysis, developed through a specific GIS, highlighted the vulnerability of the brick masonry spires on top of belfries in the 2012 Emilia earthquake area. Despite the significance of this problem for the conservation of this peculiar element of our cultural heritage, it has not been widely inspected in the scientific literature. Moreover, often numerical models applied to these towers have disregarded or underestimated this risk. In these 
cases it is important to recover the experience of the real past behaviour of these structures to identify their vulnerabilities, to compare their behaviour, identifying recurring damages also in relation to the specific building technologies, and to define possible interventions to prevent future damages.

This type of analysis at a territorial scale takes large advantage of the use of GIS and could be reproduced also for other building typologies and for other earthquakes; not only to understand the health state of architectural heritage, but also to act before the expected damage occurs.

In this perspective, the designed GIS geodatabase represents a proactive tool for the analysis and prevention of the seismic risk of the architectural heritage. Uploading in GIS software the seismic hazard maps can allow to identify the elements which are mostly in danger, given their expected seismic action. This predictive approach could allow to define the most urgent interventions and to plan a preventive maintenance program.

In addition the assets are georeferenced, a great advantage in emergency situations, because it could ensure a more rapid and efficient phase of expedition survey. Indeed, shakemaps of an earthquake, produced in real time by INGV, make it possible to know immediately the accelerations to which each element was subjected and, thanks to the analysis of the previous damages, foresee what damage could likely have occurred.

In order to avoid the loss of the top of the spire, some proposals have been put forward, but the results of the dynamic analyses show that the different proposals have different efficacy levels depending on the specific features: a demonstration that there is not an "absolute" best solution, but an intervention suitable for each case, as always should be in restoration.

\section{REFERENCES}

Arcoraci, L., Berardi, M., Bernardini, F. et al., 2012. Rapporto macrosismico sui terremoti del 20 (Ml 5.9) e del 29 maggio 2012 (Ml 5.8 e 5.3) nella pianura Padano-Emiliana, QUEST-INGV, www. ingv. it .

Baratta, M.,1901. I terremoti d'Italia: Saggio di storia, geografia e bibliografia sismica italiana con 136 sismogrammi, Fratelli Bocca Editori, Torino.

Bayraktar, A., Altunişik, A. C., Sevim, B., \& Türker, T. 2011a. Seismic response of a historical masonry minaret using a finite element model updated with operational modal testing. Journal of Vibration and Control, 17(1), 129-149.

Blasi, C. (Eds.),2013. Architettura storica e Terremoti: Protocolli operativi per la conoscenza e la tutela, Wolters Kluwers, Milano.

Blasi, C., 2014. Il consolidamento dei campanili danneggiati dal sisma: riflessioni su conservazione e sicurezza, in: Di Francesco C. (Eds.), A sei mesi dal sisma, Bologna, pp.225-237

Cigada, A., Corradi Dell'Acqua, L., Mörlin Visconti Castiglione, B., Scaccabarozzi, M., Vanali, M., Zappa, E. 2017a, Structural health monitoring of an historical building: The main spire of the Duomo di Milano, International Journal of Architectural Heritage, 1.4, 501-518.

Causevic, A., Idrizbegovic-Zgonic, A., Rustempasic, N., \& Handzic, L. K. 2019a. Restoring Minarets as A Dominant Part of
Urban Landscape Restoration of Stone and Wooden Minarets in Bosnia and Herzegovina-Materials, Structure and Urban Form. In IOP Conference Series: Materials Science and Engineering (Vol. 471, No. 8, p. 082003). IOP Publishing.

Coïsson, E., Ferretti D., Lenticchia, E., 2017a. Analysis of damage mechanisms suffered by Italian fortified buildings hit by earthquakes in the last 40 years, Bulletin of Earthquake Engineering 15.12, 5139-5166.

De Jong, M. J., 2012a. Seismic response of stone masonry spires: Analytical modeling, Engineering Structures, 40, 556-565.

Di Cocco, I., 2014. Dalla lista dei danni alla mappa del tesoro. [...], in: Di Francesco C. (Eds.), A sei mesi dal sisma, Bologna, pp.119-120

Dizhur, D., Lumantarna, R., Ismail, N., Ingham, J. M., \& Knox, C., 2010a. Performance of unreinforced and retrofitted masonry buildings during the 2010 Darfield earthquake. Bulletin of the New Zealand Society for Earthquake Engineering, 43(4), 321.

Doğangün, A., Sezen, H., Tuluk, Ö. İ., Livaoğlu, R. \& Acar, R., 2007a. Traditional Turkish Masonry Monumental Structures and their Earthquake Response, International Journal of Architectural Heritage, 1:3, 251-271, DOI: $10.1080 / 15583050701436980$

Doglioni, F., Moretti A., Petrini V., 1994. Le chiese e il terremoto, Ed. LINT, Trento.

Elyamani, A., 2016a. Conservation-oriented structural analysis of the spire of Barcelona cathedral. International Journal of Materials Science and Applications, 5(6-2), 1-9.

ESRI, 2019. ArcGIS Pro, https://www.esri.com/enus/arcgis/products/arcgis-pro/overview. (11 March 2019).

Ferretti, D.; Coïsson E., 2014a. The seismic vulnerability of towers' masonry spires: learning from history. Proceedings of the 9th International Conference on Structural Analysis of Historical Construction, ISBN:978-3-43360-444-1

Goodchild, M., Maguire D., Rhind D., 1991. Geographic Information Systems: Principles and Applications (2 Vol.), Longman.

Guidoboni, E., Boschi, E., 1991. I grandi terremoti medioevali in Italia, in Le Scienze.

INGV, 2019. Shakemaps Archive, http://shakemap.rm.ingv.it/shake/archive/. (28 February 2019).

INGV, 2018. Le shakemap: una pronta ed efficace visualizzazione dello scuotimento prodotto da un terremoto, https://ingvterremoti.wordpress.com/2016/09/05/le-shakemapuna-pronta-ed-efficace-visualizzazione-dello-scuotimentoprodotto-da-unterremoto/. (20 January 2018).

INGV, 2018 Catalogo Parametrico dei Terremoti Italiani https:/emidius.mi.ingv.it/CPTI15-DBMI15/. (23 January 2018).

INGV, 2018. ISMD. http://ismd.mi.ingv.it/ismd.php. (29 January 2018). 
INGV, 2018. I terremoti storici in Italia. http://ingv.maps.arcgis.com/apps/MapTour/index.html?appid=8 f549431a8bf4cdab60429ba0b3d0352\#. (29 January 2018).

Mehrotra, A., \& DeJong, M. J. 2017a. A modelling tool for dynamic analysis of masonry collapse mechanisms. Proceedings of the 16th World Conference on Earthquake Engineering.

Ministry for Cultural Heritage and Activities, 2008. Guidelines for the evaluation and mitigation of seismic risk to cultural heritage, Gangemi Editore, Roma, ISBN10 88-492-1269-0.

Nohutcu, H., 2019a. Seismic Failure Pattern Prediction in a Historical Masonry Minaret under Different Earthquakes. Advances in Civil Engineering.

Steinitz, C., 2012. A Framework for Geodesign, Esri Press.

USGS, 2018.2 Latest Earthquakes..https://earthquake.usgs.gov/earthquakes/map. (31 January 2018).

USGS, 2019. Search Earthquake Catalog, https://earthquake.usgs.gov/earthquakes/search/ (4 March 2019).

Zanazzi E., 2017. BALANCING ON TIPTOES, Overview of the spires damaged by 2012 earthquake, georeferenced analysis and strengthening proposals, thesis in Architecture, University of Parma, Tutors E. Coïsson, D. Ferretti, B. Caselli. 